\title{
Preparation and Characterization of Wound Dressings Incorporated with Curcumin, Povidone Iodine, and Silver Sulphadiazine
}

\author{
Kavitha Bangarakodi ${ }^{1}$, Deveswaran Rajamanickam 1,*(D), Anbu Jeyaraman ${ }^{2}(\mathbb{D}$, \\ Bharath Srinivasan ${ }^{1}$ (D) \\ 1 Department of Pharmaceutics, Faculty of Pharmacy, M.S. Ramaiah University of Applied Sciences, Bangalore- 560054 , \\ Karnataka, India \\ 2 Department of Pharmacology, Faculty of Pharmacy, M.S. Ramaiah University of Applied Sciences, Bangalore- 560054 , \\ Karnataka, India \\ * Correspondence: deveswaran.ps.ph@msruas.ac.in;
}

Scopus Author ID 25229806200

Received: 4.09.2020; Revised: 29.09.2020; Accepted: 30.09.2020; Published: 2.10.2020

\begin{abstract}
The present study was intended to develop a delivery system for wound care by incorporating Povidone-iodine, Curcumin, and silver sulfadiazine. Chitosan, a polymer derived from a natural source containing antimicrobial property, was used in the dressings. Polyethylene glycol 6000 was used as a film-forming polymer, and polyvinylpyrrolidone was used as a plasticizer. Gelatin was used to increase the swelling property. The prepared wound dressings were found to be acceptable from the evaluation tests carried out like viscosity, thickness, swelling study, drug content. Pores were observed on the surface; the texture was found to be rough. The prepared formulation was found to be stable in terms of drug content during the stability study. The release of drug was prolonged up to 4hours, and the in-vivo studies depicted excellent wound healing activity. Thus, in conclusion, the applications of this wound dressings can be explored in vast range by various methodologies and formulations in the near future for effective wound management.
\end{abstract}

Keywords: chitosan; wound dressings; povidone; curcumin; silver sulfadiazine.

(C) 2020 by the authors. This article is an open-access article distributed under the terms and conditions of the Creative Commons Attribution (CC BY) license (https://creativecommons.org/licenses/by/4.0/).

\section{Introduction}

The wound is defined as the disruption of the anatomic and cellular continuity of tissue caused by chemical, physical, thermal, microbial, or immunological injury to the tissue [1]. Wound healing is a process of replacement of dead tissue with healthy functional tissue. Both surfaces should be close enough to each other for an effective process of tissue bridging among them. Wound healing is defined as the replacement of damaged tissue with the new living tissue. Many cells and its components act together to regenerate the wounded tissue. It basically consists of four phases, which include hemostasis, inflammatory phase, proliferative phase, and maturation [2]. The main ambition of wound care is to provide the faster healing leaving behind a minimum scar and also prevent infection. The healing rate is decreased by several factors, which include ischemia, dry wound environment, infection, nutritional deficiency, foreign bodies, etc. The wound dressing is a treatment given to skin in which the chemicals added to the preparation form a layer and adhere to the skin. It helps in preventing the wound from germs and dust. Wound dressing has a composition that provides a protective layer to the 
cuts, wounds, abrasions, scrapes, and prevents the further progression of the wound. The application of these wound dressings to open wounds will form a sealing on the wounds leading to a decrease in contamination in the affected area and encourages faster healing [3]. Wound dressings may contain antimicrobials, antiseptics, or antibiotics and can be applied to control wound infections. It also reduces the risk of unnecessary effects as they act locally more than systemically. The ideal topical antimicrobial drug should have broad activity and must be safe to use without being allergenic [4]. In order to fasten or ease the regeneration or wound healing, adequate moisture plays an important role and must be retained in the dressing [5]. An ideal wound dressing should retain a favorable moisture environment at the wound surface and prevent dehydration [6]. Conventional gauze bandages and plasters do not protect wounds from infection and water and must be changed often. Thus, these conventional wound coverings often interfere with healing, inhibit normal bathing of the area around the wound, and are uneconomical in terms of time required for changing [7]. To protect the wound or affected area from airborne bacteria and dirt, dressings should have moisture vapor permeability sufficient to prevent the accumulation of aqueous fluid under the bandage, non-toxic and non-irritating to the skin, should not cause burning or stinging sensation when applied, and should be readily removable when desired [8].

By providing moisture to the wound, wound dressings create a moist healing environment, which promotes granulation, epithelialization, and autolytic debridement. The wound dressing may help in providing mechanical protection to wound, prevent microbial contamination and loss of moisture, delivery of therapeutic agent in a proper ratio. Previously reported literature revealed that Anjum et al. (2016) have worked on the development of antimicrobial and scar preventive chitosan hydrogel wound dressings using chitosan, polyethylene glycol, and polyvinyl alcohol as polymers [9]. Novel chitin/chitosan-glucan wound dressing [10] was developed by Mohsen et al. (2016); Zohdi et al. (2011), worked on gelam (Melaleuca spp.) honey-based hydrogel [11] as burn wound dressing, Harish, T. et al. (2013), worked on in-situ liquid bandages of diclofenac sodium as film dressing [12] and Akturk. O et al. (2010) worked on Sericin-collagen membranes as a wound dressing [13] with polyvinyl alcohol/dextran hydrogel. In this study, a prototype of a delivery system in the wound care segment containing chitosan, povidone-iodine, silver sulphadiazine, and curcumin was developed with the intention of faster healing of the wounds in an excision wound model. The developed wound dressings were characterized in terms of rheological properties, thickness, and swelling ratio. The surface morphology was examined using scanning electron microscopy, and the in-vitro drug release was conducted using Kishery-Chien diffusion cells. The in-vivo animal study was undertaken to evaluate the effect dressings on the wound in rats using the Excision wound model.

\section{Materials and Methods}

Chitosan was purchased from Himedia Laboratories Pvt. Ltd. Mumbai, India, Silver sulfadiazine, PEG 6000, and glacial acetic acid was obtained from Spectrochem Pvt. Ltd. Mumbai, PVP K30 was obtained from Yarrow chem. Products, Mumbai, Isopropyl alcohol, was purchased from Ranbaxy Fine Chemicals Limited; Gelatin was a product from Thermo Fisher Scientific India Pvt. Ltd, Mumbai. Povidone-iodine was obtained from Adani Pharmachem Pvt. Ltd. Rajkot. Curcumin extract was a gift sample from Prakruti Products Pvt. Ltd. Karwar, Karnataka. All other reagents used were of analytical grade. 


\subsection{Formulation of wound dressings.}

Dressings were prepared by the dip-coating method [14]. The method was modified according to the laboratory conditions. Chitosan (2\%) was dissolved in $2 \%$ acetic acid solution. PEG 6000 (2\%) and PVP K 30(0.25\%) was dissolved in chitosan solution and mixed well. Drugs were dissolved in isopropyl alcohol and poured into the blend solution. The drugs used were povidone-iodine, curcumin, and silver sulfadiazine. A suitable dressing material, namely plain cotton cloth, gauze bandage, and gauze with cotton with an area of $25 \mathrm{sq} . \mathrm{cm}$, was cut and placed in a Petri plate. The blend was poured to this material so that the material was completely dipped in the chitosan/PEG/PVP blend. It was then dried in a hot air oven at $50^{\circ} \mathrm{C}$ for $24 \mathrm{hrs}$. The composition of the wound dressings bandages is shown in Table 1. The dried wound dressings were stored in a desiccator and evaluated for further studies.

Table 1. Formulation of wound dressings.

\begin{tabular}{|c|c|c|c|c|c|c|c|c|c|c|c|c|}
\hline Ingredients & CH1 & CH2 & CH3 & PI 1 & PI 2 & PI 3 & CU 1 & CU 2 & CU 3 & SS 1 & SS 2 & SS 3 \\
\hline $\begin{array}{l}\text { Dressing } \\
\text { used }\end{array}$ & Cloth & Gauze & $\begin{array}{l}\text { Gauze+ } \\
\text { cotton }\end{array}$ & Cloth & Gauze & $\begin{array}{l}\text { Gauze+ } \\
\text { cotton }\end{array}$ & Cloth & Gauze & $\begin{array}{l}\text { Gauze+ } \\
\text { cotton }\end{array}$ & Cloth & Gauze & $\begin{array}{l}\text { Gauze } \\
\text { +cotton }\end{array}$ \\
\hline $\begin{array}{l}\text { Povidone } \\
\text { iodine }\end{array}$ & - & - & - & $\begin{array}{l}2.5 \mathrm{~g} \\
(5 \%)\end{array}$ & $\begin{array}{l}2.5 \mathrm{~g} \\
(5 \%)\end{array}$ & $\begin{array}{l}2.5 \mathrm{~g} \\
(5 \%) \\
\end{array}$ & - & - & - & - & - & - \\
\hline Curcumin & - & - & - & - & - & - & $\begin{array}{l}2.5 \mathrm{~g} \\
(5 \%)\end{array}$ & $\begin{array}{l}2.5 \mathrm{~g} \\
(5 \%)\end{array}$ & $\begin{array}{l}2.5 \mathrm{~g} \\
(5 \%)\end{array}$ & - & - & - \\
\hline $\begin{array}{l}\text { Silver } \\
\text { Sulfadiazine }\end{array}$ & - & - & - & - & - & - & - & - & - & $\begin{array}{l}2.5 \mathrm{~g} \\
(5 \%)\end{array}$ & $\begin{array}{l}2.5 \mathrm{~g} \\
(5 \%)\end{array}$ & $\begin{array}{l}2.5 \mathrm{~g} \\
(5 \%)\end{array}$ \\
\hline Chitosan & $1 \mathrm{~g}$ & $1 \mathrm{~g}$ & $1 \mathrm{~g}$ & $1 \mathrm{~g}$ & $1 \mathrm{~g}$ & $1 \mathrm{~g}$ & $1 \mathrm{~g}$ & $1 \mathrm{~g}$ & $1 \mathrm{~g}$ & $1 \mathrm{~g}$ & $1 \mathrm{~g}$ & $1 \mathrm{~g}$ \\
\hline PEG6000 & $1 \mathrm{~g}$ & $1 g$ & $1 \mathrm{~g}$ & $1 \mathrm{~g}$ & $1 \mathrm{~g}$ & $1 \mathrm{~g}$ & $1 \mathrm{~g}$ & $1 \mathrm{~g}$ & $1 \mathrm{~g}$ & $1 \mathrm{~g}$ & $1 \mathrm{~g}$ & $1 \mathrm{~g}$ \\
\hline PVP K 30 & $0.5 \mathrm{~g}$ & $0.5 \mathrm{~g}$ & $0.5 \mathrm{~g}$ & $0.5 \mathrm{~g}$ & $0.5 \mathrm{~g}$ & $0.5 \mathrm{~g}$ & $0.5 \mathrm{~g}$ & $0.5 \mathrm{~g}$ & $0.5 \mathrm{~g}$ & $0.5 \mathrm{~g}$ & $0.5 \mathrm{~g}$ & $0.5 \mathrm{~g}$ \\
\hline Gelatin & - & - & - & - & - & - & - & - & - & $\begin{array}{l}2.5 \mathrm{~g} \\
(5 \%)\end{array}$ & $\begin{array}{l}2.5 \mathrm{~g} \\
(5 \%)\end{array}$ & $\begin{array}{l}2.5 \mathrm{~g} \\
(5 \%)\end{array}$ \\
\hline $\begin{array}{l}2 \% \quad \text { Acetic } \\
\text { acid }\end{array}$ & $50 \mathrm{ml}$ & $50 \mathrm{ml}$ & $50 \mathrm{ml}$ & $40 \mathrm{ml}$ & $40 \mathrm{ml}$ & $40 \mathrm{ml}$ & $40 \mathrm{ml}$ & $40 \mathrm{ml}$ & $40 \mathrm{ml}$ & $40 \mathrm{ml}$ & $40 \mathrm{ml}$ & $40 \mathrm{ml}$ \\
\hline Water & - & - & - & - & - & - & - & - & - & $10 \mathrm{ml}$ & $10 \mathrm{ml}$ & $10 \mathrm{ml}$ \\
\hline IPA & - & - & - & $10 \mathrm{ml}$ & $10 \mathrm{ml}$ & $10 \mathrm{ml}$ & $10 \mathrm{ml}$ & $10 \mathrm{ml}$ & $10 \mathrm{ml}$ & - & - & - \\
\hline
\end{tabular}

2.2. Evaluation of wound dressings.

2.2.1. Fourier transformed infrared spectroscopy.

The FT-IR of pure drug and physical mixture of pure drug with the excipients used in the formulation was measured using Fourier Transform Infra-Red Spectrophotometer. Pure drug and physical mixture of pure drug with the excipients were mixed with IR grade potassium bromide and converted into pellet by hydraulic press [15]. The resulting pellets were scanned over a range of $400-4000 \mathrm{~cm}^{-1}$.

\subsubsection{Viscosity of the solution.}

Before the blend solution was poured to the Petri dish, the viscosity of the blend solution was determined using Brookfield viscometer (Spindle IV) at varying rpm of $10,20,30,50$ and 100 .

\subsubsection{Thickness of wound dressings.}

The thickness of the wound dressing was measured using a Screw gauge. The thickness was measured at three different places in a dressing. The values were recorded, and the thickness was calculated using the following formula.

Total reading $(\mathrm{TR})=$ Pitch Scale reading $(\mathrm{PSR})+$ Head Scale reading $(\mathrm{HSR}) *$ Least Count $(\mathrm{LC})$ 
The average of three readings was taken as the thickness of the dressing

\subsubsection{Tensile strength.}

The tensile strength of the prepared wound dressings was evaluated using a fabricated instrument. Wound dressings of dimension 20x10 mm and free from air bubbles or physical imperfections were held between two clamps, which are supported on a metal base. One of the clamps was fixed, and the other one was movable, which was tied to the weighing pan. During measurement, the strips were pulled by the movable clamp with the addition of weights [16]. The strength and elongation were measured when the dressings broke or changed its shape completely, and tensile strength was calculated using the formula:

Tensile Strength $=$ Tensile load at break/Cross-sectional area

\subsubsection{Scanning electron microscopy.}

The surface morphology of the selected wound dressing was observed by scanning electron microscopy (SEM) using Zeiss, Ultra 55 Scanning Electron Microscope. The sample was prepared by attaching the wound dressing onto the slab with double-sided adhesive tape and coated with gold prior to microscopic examination.

\subsubsection{Swelling studies.}

The prepared wound dressings were cut into $1.5 \mathrm{sq} . \mathrm{cm}$ and weighed. The samples were placed in water for 24 hours and observed. Swollen samples were taken out from the water and blotted using absorbent paper to remove the excess dripping water and weighed again [17]. The readings were measured at $0,1,2,3,4,5$, and $24 \mathrm{hrs}$, respectively. The swelling ratio was calculated using the formula

$$
\text { Swelling ratio }(\%)=\frac{\mathrm{Ws}-\mathrm{Wd}}{\mathrm{Wd}} * 100
$$

Where Ws $=$ Weight of wet sample, $\mathrm{Wd}=$ Weight of dry sample

\subsubsection{Drug content estimation.}

The amount of drug-loaded was found on the basis of the area of dressing. From the prepared dressing, $1 \mathrm{~cm}^{2}$ was taken and mixed with $25 \mathrm{ml}$ of phosphate buffer $\mathrm{pH} 7.4$, sonicated for the complete dissolution of the contents present in the dressing. The resulting solution was filtered, and absorbance of the filtrate was measured spectrophotometrically at $231.5 \mathrm{~nm}$ for povidone-iodine, $457 \mathrm{~nm}$ for curcumin, and $452.5 \mathrm{~nm}$ for silver sulfadiazine, respectively.

\subsubsection{In-vitro drug release studies and release kinetics.}

The drug release pattern of the prepared wound dressing was evaluated using the Kishery-Chien diffusion cell. Each cell had a volume of $14 \mathrm{ml}$ and a diffusion diameter of $2 \mathrm{~cm}$. The dressings were cut with a diameter equal to the diameter of the cell and mounted between the donor and receptor compartment. The receptor compartment was filled with phosphate buffer $\mathrm{pH} 7.4$ and stirred at a 70rpm using a magnetic stirrer. At suitable time intervals, a sample of $1 \mathrm{ml}$ was withdrawn from each cell and replaced with the same volume of fresh samples to maintain sink conditions. The samples were diluted accordingly, and the absorbance was measured using a UV-Visible spectrophotometer at $\lambda$ max of $231.5 \mathrm{~nm}$ for Povidone-iodine, 
$457 \mathrm{~nm}$ for curcumin, and $452.5 \mathrm{~nm}$ for silver sulfadiazine, respectively. To analyze the drug release kinetics and mechanism of the drug release from the prepared wound dressings, the invitro diffusion studies were fitted into Zero order, First order, Higuchi Matrix, Hixson- Crowell cube root law model, and Korsmeyer- Peppas equations using PCP- Disso. V3 [18].

\subsection{Wound healing studies.}

The in-vivo studies of developed wound dressings were carried out by the excision wound model in rats. Wound healing activity of the prepared wound dressings was carried out using Wistar albino rats weighing 200-300g. Rats were divided into 5 groups of 6 animals each. The groups with the type of composition are as follows: Group I was control; Group II animals were treated with povidone-iodine marketed ointment (Betadine); Group III animals were treated with wound dressing containing povidone-iodine; Group IV animals were treated with wound dressing containing curcumin, and Group V animals were treated with wound dressing containing silver sulphadiazine respectively. The rats were anesthetized by intraperitoneal injection of Ketamine hydrochloride $(15 \mathrm{mg} / \mathrm{kg}$, ip) and Lignocaine $(60 \mathrm{mg} / \mathrm{kg}$, ip). The dorsal skin of the animal was shaved using a sterile scalpel blade. The region $1 \mathrm{~cm}$ below the forelimb and $1 \mathrm{~cm}$ above the hind limb was selected. In each animal, four divisions were made, and wounds were created in each division, measuring approximately $1 \mathrm{~cm}$ in diameter. Wounds were treated with selected wound dressings. The diameter of the wound was measured on 3rd, 6th, 9th, 12 th, and $15^{\text {th }}$ day.

\subsection{Stability studies.}

Stability studies were carried out as per ICH guidelines [19] at the temperature of $40^{\circ} \mathrm{C} \pm 2^{\circ} \mathrm{C}$ with $75 \pm 5 \% \mathrm{RH}$ for the selected formulations for 3 months. The prepared wound dressings were packed in airtight packaging material, placed in a stability chamber, and evaluated for drug content at suitable time intervals.

\section{Results and Discussion}

\subsection{Formulation of wound dressings.}

Formulation of wound dressing included the incorporation of drugs povidone-iodine, curcumin, and silver sulfadiazine in different dressing materials like plain cotton cloth, gauze bandage, and gauze with cotton. Povidone-iodine and curcumin possess the antiseptic property, and silver sulfadiazine has antimicrobial properties. These drugs help in the faster healing of the wound. On the other hand, chitosan also has antimicrobial property, which adds on to the property of the drugs incorporated. PEG 6000 acts as a film-forming polymer and PVP K-30 acts as a plasticizer. A total of 12 formulations were developed in 4 batches; each batch consists of wound dressings of plain cotton cloth, gauze bandage, and gauze with cotton, each containing chitosan, povidone-iodine, curcumin, and silver sulfadiazine respectively.

\subsection{Drug-excipients compatibility studies.}

Fourier Transform Infrared Spectroscopy was performed for Povidone-iodine, Curcumin, Silversulfadiazine, Chitosan, PEG 6000, PVP K 30, and physical mixtures of drugs with polymers to detect any sign of interactions which would be reflected by any change in the position or disappearance of any characteristic peaks of the compound. Pure drug and the 
physical mixture of drug and polymer were subjected to Fourier transformed infrared spectroscopic studies. FT-IR spectrum of Povidone-iodine (Fig. 1A) showed characteristic peak for C-I at $538.10 \mathrm{~cm}^{-1}$ peaks in the region ranging from $1670 \mathrm{~cm}^{-1}$ to $1820 \mathrm{~cm}^{-1}$ that confirmed the presence of $\mathrm{C}=\mathrm{Obond}$, peaks for $\mathrm{C}-\mathrm{H}$ stretch were in the region ranging from $2800 \mathrm{~cm}^{-1}-2930 \mathrm{~cm}^{-1}$. Chitosan showed characteristic peaks at $2840-3000 \mathrm{~cm}^{-1}$ signifying C-H stretch. Small peaks of O-C-O were seen in the range of $1020-1275 \mathrm{~cm}^{-1}$. NH and $\mathrm{OH}$ stretches were observed in between $3350-3310$ and $3420-3590 \mathrm{~cm}^{-1}$, respectively. The band at 1666 $\mathrm{cm}^{-1}$ assigned for $\mathrm{NH}$ bending, and the small peak between 1600 and $1650 \mathrm{~cm}^{-1}$ attributed to $\mathrm{C}=\mathrm{O}$ stretching. Bands at 2927 and $2884 \mathrm{~cm}^{-1}$ and a small peak between 1400 and $1420 \mathrm{~cm}^{-1}$ was assigned to $\mathrm{CH} 2$ bending of pyranose ring. Bands around $1400 \mathrm{~cm}^{-1}$ are due to $\mathrm{CH} 3$ wagging [20] (Fig. 1B, 2B, 3B). PEG 6000 showed characteristic peaks at 1020.27 $\mathrm{cm}^{-1}$ signifying C-O stretches, $1097.42 \mathrm{~cm}^{-1}$ signifies C-O-C stretch, and $3103.25 \mathrm{~cm}^{-1}$ attributed to $\mathrm{O}-\mathrm{H}$ stretch (Fig. 1C, 2C, 3C). PVP K-30 showed characteristic peaks at 2879.52 $\mathrm{cm}^{-1}$ attributed to $\mathrm{C}-\mathrm{H}$ stretch, $170881 \mathrm{~cm}^{-1}$ signified $\mathrm{C}=\mathrm{O}$ stretch, and $3352.05 \mathrm{~cm}^{-1}$ attributed to N-H stretch (Fig. 1D, 2D, 3D). FT-IR spectrum of Curcumin (Fig. 2A) showed the peaks ranging from $1050 \mathrm{~cm}^{-1}-1150 \mathrm{~cm}^{-1}$ for $\mathrm{C}-\mathrm{O}$ stretch, from $3010 \mathrm{~cm}^{-1}-3100 \mathrm{~cm}^{-1}$ for $=\mathrm{C}-\mathrm{H}$ bond and from $3200 \mathrm{~cm}^{-1}-3700 \mathrm{~cm}^{-1}$ at O-H stretch.FT-IR spectrum of Silver sulfadiazine (Fig. 3A) showed a characteristic peak for $\mathrm{S}=\mathrm{O}$ in the range of $1360 \mathrm{~cm}^{-1}-1375 \mathrm{~cm}^{-1}$. Peaks were observed in the region ranging from $3170 \mathrm{~cm}^{-1}-3500 \mathrm{~cm}^{-1}$ for N-H stretch, from $1080 \mathrm{~cm}^{-1}$ $1360 \mathrm{~cm}^{-1}$ for $\mathrm{C}-\mathrm{N}$ bond and from $3200 \mathrm{~cm}^{-1}-3700 \mathrm{~cm}^{-1}$ for $\mathrm{OH}$ bond. Similar peaks were observed in the same region in the spectrum of a physical mixture of drug and polymer. From the IR spectral analysis, the expected characteristic absorption peaks for the pure drugs was observed in the IR spectra obtained for the mixture of drug with the excipients. This confirmed that drugs and the excipients used were found to be compatible.

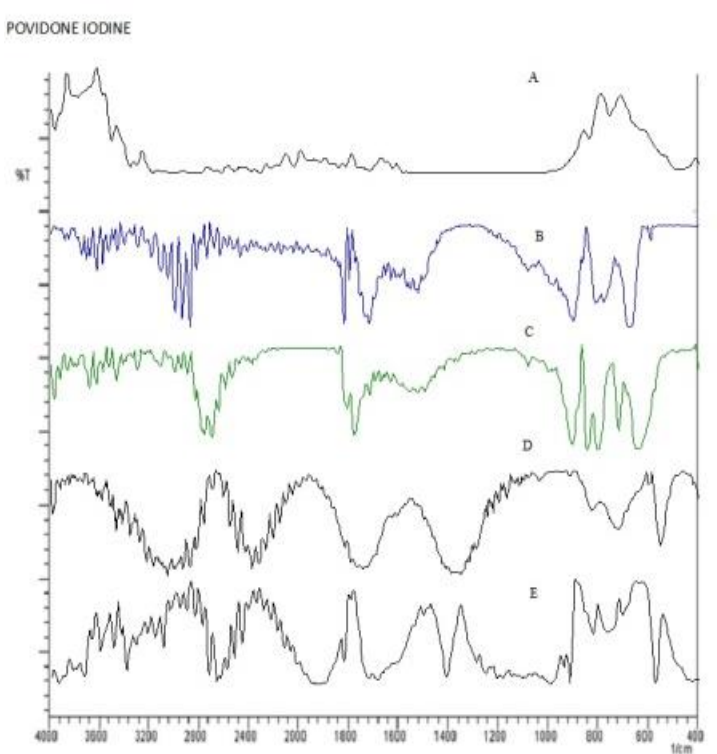

Figure 1. FT-IR spectrum of (A) Povidone, (B)chitosan, (C) PEG 6000, (D) PVP K30, (E) Physical mixture of povidone with excipients.

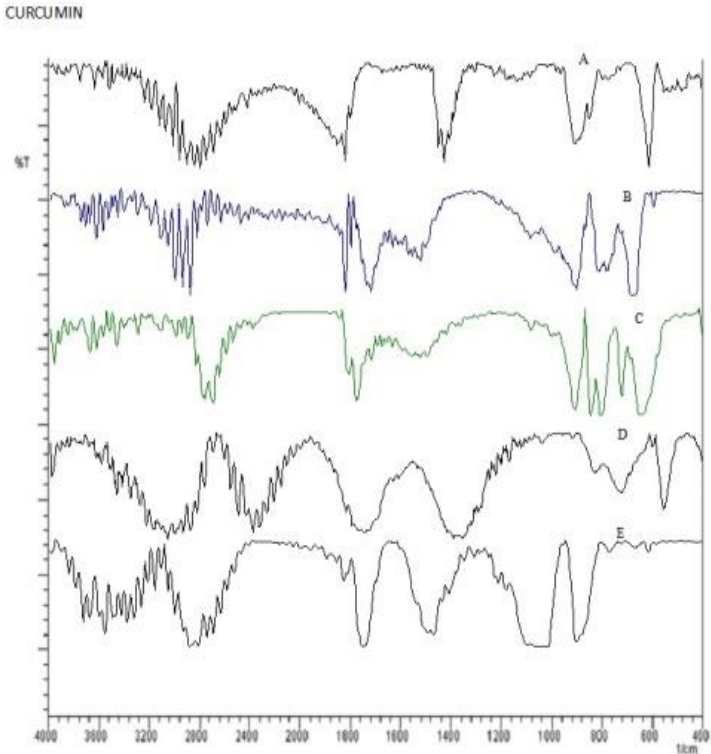

Figure 2. FT-IR spectrum of (A) pure curcumin, (B)chitosan, (C) PEG 6000, (D) PVP K30, (E) Physical mixture of curcumin with excipients.

\subsection{Viscosity of blend solutions.}

The viscosity of the blend solution of all the ingredients was measured. Chitosan blend solution causes higher shear stress in the polymeric blend and consequently, a high viscosity. 
The polymeric combinations used in the formulation preparation are relatively hydrophilic and miscible in nature.

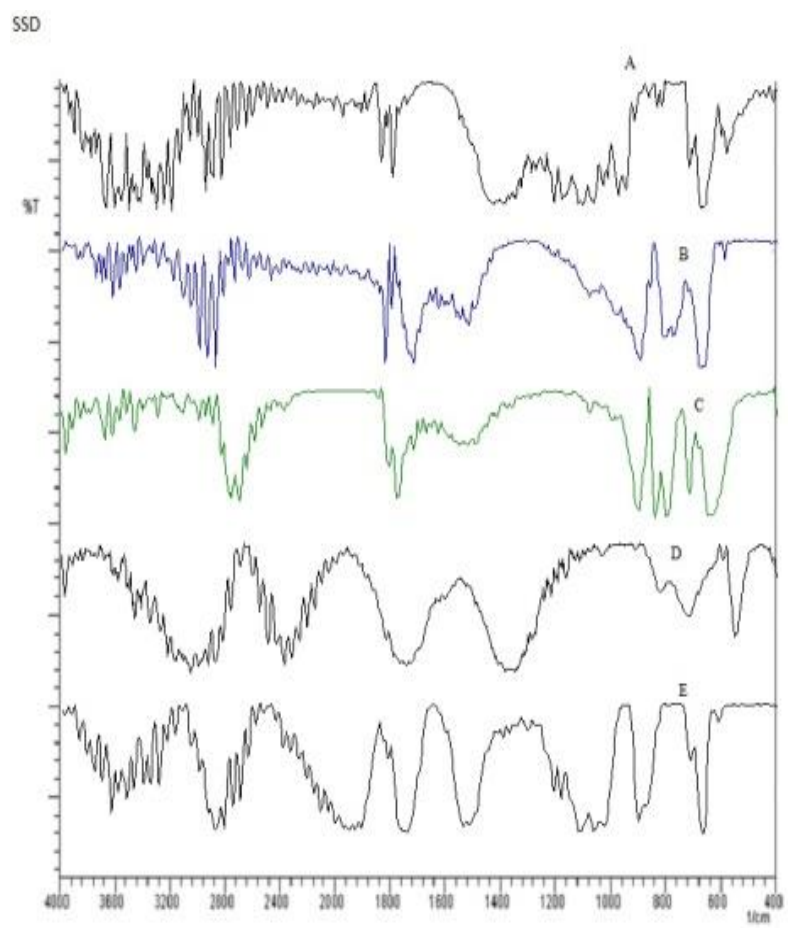

Figure 3. FT-IR spectrum of (A) Silver sulphadiazine, (B)chitosan, (C) PEG 6000, (D) PVP K30, (E) Physical mixture of silver sulphadiazine with excipients.

The miscibility, in turn, may be attributed to the typical interactions between polymeric components such as covalent bonding, electrostatic interactions, hydrogen bonds, and dipoledipole interactions, among others, which also attributes to the typical viscosity of the formulations. Chitosan blend solution showed 56.3cps and 15.4cps, Povidone-chitosan blend showed 52.5cps and $19.5 \mathrm{cps}$, Curcumin-chitosan blend showed 56.3cps and 21.8cps, and Silver sulfadiazine- chitosan blend showed 36.6 and $9.75 \mathrm{cps}$ at 10 and $100 \mathrm{rpm}$ respectively. Compared to all blend solutions, the blend containing Silver sulfadiazine was found to be less viscous. As the rpm increased, the viscosity decreased, thereby confirming the shear thinning nature of the prepared blend solutions. One of the important requirements of dressings in wound healing activity is that the dressings should be able to retain an adequately high viscosity in order to inhibit flow for a longer period of time when applying to the wound surfaces [21]. The prepared wound dressings have the capability of holding the integrity of the hydrogel with a higher interpolymeric strength that is helpful for a prolonged activity of the formulations in wound healing.

\subsection{Thickness of dressings.}

The thickness of the different formulations prepared ranged from $0.07 \mathrm{~mm}$ to $0.22 \mathrm{~mm}$. The wound dressings made of gauze with cotton as dressing material showed greater thickness than other materials. The values of thickness of the prepared wound dressings were $0.07 \mathrm{~mm}$, $0.11 \mathrm{~mm}, 0.20 \mathrm{~mm}, 0.14 \mathrm{~mm}, 0.14 \mathrm{~mm}, 0.20 \mathrm{~mm}, 0.17 \mathrm{~mm}, 0.14 \mathrm{~mm}, 0.20 \mathrm{~mm}, 0.17 \mathrm{~mm}, 0.22 \mathrm{~mm}$, and $0.19 \mathrm{~mm}$ respectively for the formulations $\mathrm{CH} 1, \mathrm{CH} 2, \mathrm{CH} 3, \mathrm{PI} 1, \mathrm{PI} 2, \mathrm{PI} 3, \mathrm{CU} 1, \mathrm{CU} 2, \mathrm{CU} 3$, SS1, SS2 and SS3. As the polymer concentration increased, the thickness of the wound dressings increased. 


\subsection{Tensile strength.}

Tensile strength is defined as the maximum stress sustained by the material. Tensile strength varied according to the composition of the formulation. The prepared wound dressings should withstand mechanical damage during production and handling. Tensile strength for Povidone iodine-based dressing was $1.2 \mathrm{~N} / \mathrm{m}^{2}$, whereas it was $1.3 \mathrm{~N} / \mathrm{m}^{2}$ and $1.6 \mathrm{~N} / \mathrm{m}^{2}$ for curcumin and silver sulphadiazine containing wound dressings, respectively. It was observed that as the concentration of polymer increased, tensile strength increased owing to its maximum strength. The wound dressings possess both flexibility and strength for desired effectiveness. The results are shown in Table 2 .

Table 2. Tensile strength of the prepared wound dressings.

\begin{tabular}{l|c} 
Wound dressings & $\begin{array}{c}\text { Tensile strength }\left(\mathbf{N} / \mathbf{m}^{\mathbf{2}}\right) \\
\text { (Mean } \pm \text { SD) }\end{array}$ \\
\hline Wound dressing PI 3 & $1.2 \pm 0.005$ \\
\hline Wound dressing CU 1 & $1.3 \pm 0.003$ \\
\hline Wound dressing SS3 & $1.6 \pm 0.006$
\end{tabular}

\subsection{Scanning electron microscopy.}

Fig. 4 shows SEM images of wound dressings of chitosan, povidone-iodine, curcumin, and silver sulfadiazine. The morphological features on the surface revealed a smooth matrix with significant integrity and minute pores. The PEG addition led to a highly porous structure. The addition of both PVP and PEG to the wound dressings are compatible and increases the porosity. PVP forms stronger hydrogen bonding with drugs, and the interaction of PVP with PEG is very limited. As a result, the system becomes more compatible with PVP addition. This is the reason that the pore size becomes less pronounced. The polymeric blend used in the formulation does not cause any significant changes in the morphological property of the wound dressings. The surface of the wound dressings was found to be comparatively smooth with lesser tortuousness, which could be attributed to the ratio of the polymer used. The polymeric blend of ratio 1:1 ratio was found to be less distressed when compared to the 1:3 ratio. This could be due to the formation of stable polymeric networks. The porous nature of the dressings helps in maintaining the moist environment as well as air permeation [22]. This helps in better and faster healing of the wound.

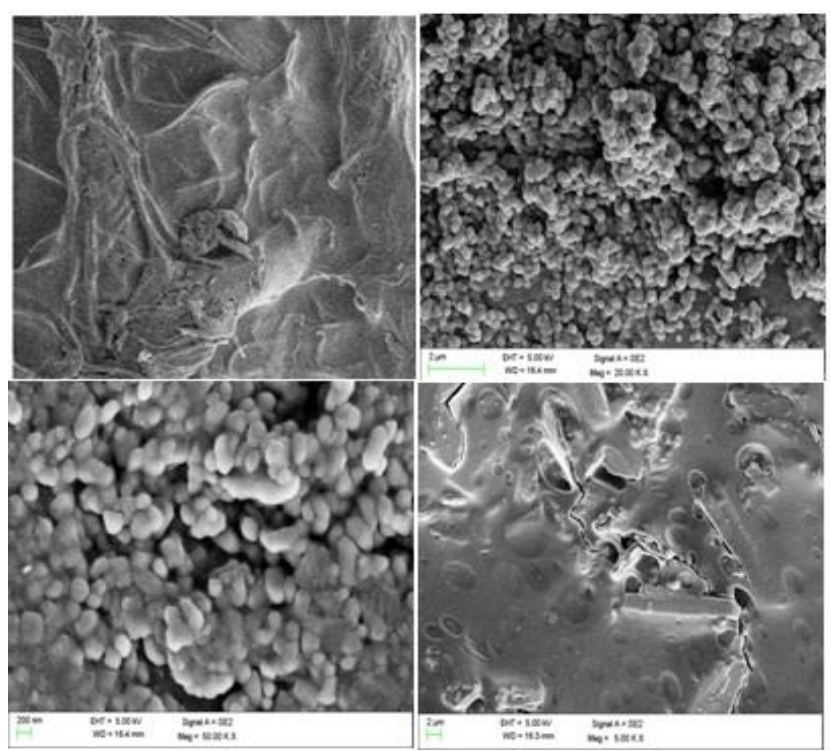

Figure 4. SEM images of (A) Chitosan wound dressings, (B)Povidone-Iodine wound dressings (C) Curcumin wound dressings, and (D) Silver sulfadiazine wound dressings. 


\subsection{Swelling studies.}

The prepared wound dressings are prone to swelling on contact with water. This was demonstrated by carrying out swelling studies for $24 \mathrm{hrs}$ in water. Swelling increased from 200 to $850 \%$ in the case of chitosan wound dressing ( $\mathrm{CH} 2>\mathrm{CH} 1>\mathrm{CH} 3)$. Chitosan is known for its increased interpolymer spacing, giving rise to an easy channeling of water, leading to a higher swelling and then erosion in the subsequent period. In the case of Povidone-iodine wound dressing (PI3>PI 2> PI 1), the swelling increased from $125 \%$ to $492 \%$, whereas in curcumin wound dressing (CU3> CU 2> CU 1), it was from $46 \%$ to $400 \%$ and $200 \%$ to $784 \%$ in case of silver sulfadiazine wound dressing (SS1>SS2>SS3) (Fig. 6). The studies confirmed that the dressings exhibit a high level of hydrophilicity and contribute to the wettability as well. No erosion was observed in any of the developed wound dressings up to 12 hours. High swelling suggests a high degree of water absorption, which might hinder the otherwise faster rate of healing and re-epithelialization process [23]. An optimum level of water absorption was observed from the studies, and this is suitable for an effective healing process.

\subsection{Drug content.}

Drug content of the wound dressings when estimated using UV-Visible spectrophotometer at $231.5 \mathrm{~nm}$ for povidone-iodine, $457 \mathrm{~nm}$ for curcumin, and $452.5 \mathrm{~nm}$ for silver sulfadiazine, the drug content was in increasing order, and they are as follows CU 1> SS 3> PI 3> PI 1> SS 2> SS 1> PI 2> CU 3> CU 2.Drug content of the wound dressings were found to be $92.17 \%, 90.22 \%, 93.07 \%, 99.56 \%, 85.49 \%, 86.13 \%, 90.25 \%, 91.84 \%$ and $93.57 \%$ for PI 1, PI 2, PI 3, CU 1, CU 2, CU 3, SS 1, SS 2 and SS 3.

\subsection{In-vitro drug release studies.}

Kieschery chain cell was used to measure the drug release from the wound dressing. Phosphate buffer $\mathrm{pH} 7.4$ was used as a diffusion medium. The percent drug release of the formulations PI1, PI 2, and PI 3 was found to be 90.69, 80.58, and 93.46, respectively. The percent drug release of the formulations CU 1, CU 2, and CU3 was found to be 91.49, 86.27, and 84.19, respectively. The percent drug release of the formulations SS 1, SS 2 and SS 3 was found to be $81.50,92.94$, and 96.18, respectively. The drug release increased till $4 \mathrm{hrs}$ and gradually decreased further. This indicated that there might be an immediate release of the drugs to the surrounding tissue, which can provide a faster healing rate. The comparative drug release profile of the prepared wound dressings was shown in Fig. 5.

\subsection{In-vitro drug release kinetics.}

In order to establish the mechanism of drug release, the experimental data were fitted to zero-order release, first-order release, Higuchi Matrix model, Hixson- Crowell model, and Korsmeyer- Peppas model using the software PCP-Disso V3. Models with the highest correlation coefficient were judged to be the most appropriate model for dissolution data. The best fit model for wound dressing SS3 was deemed to be Korsmeyer- Peppas model with an R-value of 0.9560, whereas other formulations showed Higuchi matrix model with R values of $0.9374,0.9173,0.9559,0.9428,0.9467,0.9584,0.9483$, and 0.9103 , respectively for PI 1, PI 2, PI 3, CU 1, CU 2, CU 3, SS 1 and SS 2 wound dressings. 


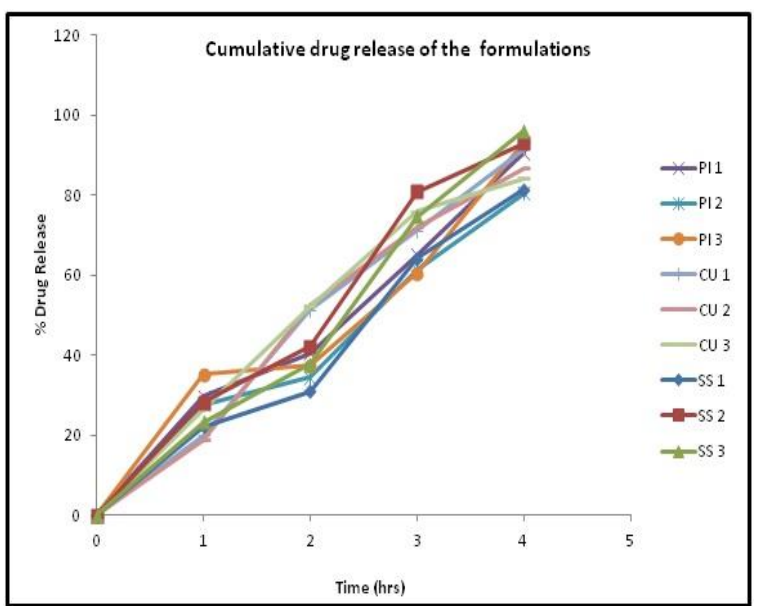

Figure 5. Comparative drug release profile of the developed formulations.

\subsection{Wound healing studies.}

The approval from the IAEC of Faculty of Pharmacy, M. S. Ramaiah University of Applied Sciences, was obtained prior to the start of the studies (XVIII/MSRFPH/M03/08.02.2018). The excision wound model was used for the study of wound healing activity. For this study, the formulations containing drugs with the highest drug release were selected irrespective of the dressing material used. Formulations PI 3, CU 1, and SS 3were selected for the wound healing activity. In this study, the povidone-iodine ointment was used as a standard. The healing process of the wounds was observed at 3, 6, 9, 12, and 15 days. There was no evidence of necrosis, and all the rats survived through the study period. There was also no indication of inflammation and hemorrhage on the animals. All the treated groups exhibited an efficient keratinocyte migration and acceleration in the re-epithelialization process. The majority of the wounds appeared to be healed and completely sealed by 7 days. All the developed wound dressings exhibited a substantial extent of healing and wound size reduction. (Fig. 6). Wound dressings of silver sulphadiazine SS3 showed a significant $(\mathrm{p}<0.01)$ extent of healing and wound size reduction from 3rd day onwards when compared to the control group, which is much faster than the other formulations. Wound dressings of curcumin and povidone-iodine (CU1 and PI3) showed a significant $(\mathrm{p}<0.01)$ extent of healing and wound size reduction from 6th day onwards when compared to the control group. This could be attributed to the presence of micropores on the surface of the wound dressings, as evident from SEM studies. Also, the dressings would create a moist environment to help in maintaining an electrical gradient between the wound and surrounding area of the skin, which may stimulate epidermal migration. It was evident that from $3^{\text {rd }}$ day onwards, the visible wound healing started in all the wound dressing formulations, and about $90-95 \%$ wound size reduction was seen. In the present study, the wound dressings greatly improved wound healing. Compared to the conventional povidone-iodine ointment, the wound dressings provided an adequate level of moisture and built up the exudates on the wound area and enhanced the wound healing process.

\subsection{Stability studies.}

The stability studies were carried out for the prepared wound dressings in accelerated conditions for a period of six months. The physical appearance was examined by storing the formulations in the airtight containers. There was no change in the physical appearance of the wound dressings. The percent drug content was found to be 92.60, 96.31 and 93.22 for wound 
dressings PI3, CU1, and SS3, respectively. This confirmed that there was no significant change in the drug content during the period of study and hence proved to be stable on storage.

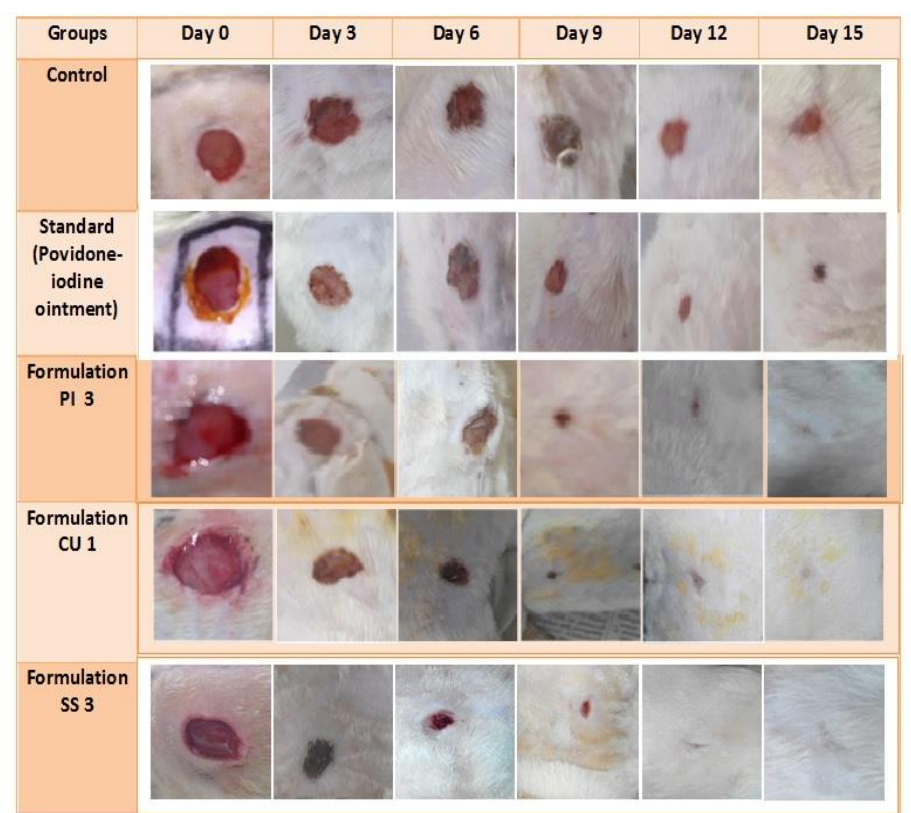

Figure 6. In vivo wound healing studies in Wistar albino rats.

\section{Conclusions}

Wound dressings of cotton cloth, gauze, and gauze with absorbent cotton incorporated with chitosan, povidone-iodine, curcumin, and silver sulphadiazine were developed and examined. The results revealed that pores present in the wound dressings provide required aeration to the wound surface, thus helping in faster healing of the wound. The immediate release of the drug helps to increase the rate of healing. The developed wound dressings absorb exudates and get stuck to the wound surface. Any dressing materials with suitable absorption capacity can also be used in this formulation of wound dressings. Since water-insoluble polymers are used, the leaching out of the contents upon contact with the water is prevented. The present work showed promising results, so this formulation and its application can be explored in vast range by various methodologies and formulations in the near future.

\section{Funding}

The authors thank M.S. Ramaiah University of Applied Sciences, MSR Nagar, Bangalore, for their support.

\section{Acknowledgments}

This research has no acknowledgment.

\section{Conflicts of Interest}

The authors declare no conflict of interest.

\section{References}

1. Visha, M.; Karunagaran, M. A review on wound healing. 2019, 3, 50-59, https://doi.org/10.4103/ijcpc.ijcpc_13_19.

2. Gurtner, G.C.; Werner, S.; Barrandon, Y.; Longaker, M.T. Wound repair and regeneration. Nature 2008, 453, 314-321, https://doi.org/10.1038/nature07039. 
3. Kennedy, J.P. Liquid Bandage and Tissue Sealant. United States Patent Application, 0030808 A1, 2006.

4. Blumenthal, K.G.; Peter, J.G.; Trubiano, J.A.; Phillips, E.J. Antibiotic allergy. The Lancet 2019, 393, 183198, https://doi.org/10.1016/S0140-6736(18)32218-9.

5. Ogawa, A.; Nakayama, S.; Uehara, M.; Mori, Y.; Takahashi, M.; Aiba, T.; Kurosaki, Y. Pharmaceutical properties of a low-substituted hydroxypropyl cellulose (L-HPC) hydrogel as a novel external dressing. International Journal of Pharmaceutics 2014, 477, 546-552, https://doi.org/10.1016/j.ijpharm.2014.10.043.

6. Marshall, C.D.; Hu, M.S.; Leavitt, T.; Barnes, L.A.; Lorenz, H.P.; Longaker, M.T. Cutaneous Scarring: Basic Science, Current Treatments, and Future Directions. Adv Wound Care (New Rochelle) 2016, 7, 29-45, https://doi.org/10.1089/wound.2016.0696.

7. Sweger, U.A. Non- Stinging Wound Dressing. United States Patent, 3932602, 1976.

8. Mir, M.; Ali, M.N.; Barakullah, A.; Gulzar, A.; Arshad, M.; Fatima, S.; Asad, M. Synthetic polymeric biomaterials for wound healing: a review. Progress in Biomaterials 2018, 7, 1-21, https://doi.org/10.1007/s40204-018-0083-4.

9. Anjum, S.; Arora, A.; Alam, M.S.; Gupta, B. Development of antimicrobial and scar preventive chitosan hydrogel wound dressings. International Journal of Pharmaceutics 2016, 508, 92-101, https://doi.org/10.1016/j.ijpharm.2016.05.013.

10. Abdel-Mohsen, A.M.; Jancar, J.; Massoud, D.; Fohlerova, Z.; Elhadidy, H.; Spotz, Z.; Hebeish, A. Novel chitin/chitosan-glucan wound dressing: Isolation, characterization, antibacterial activity and wound healing properties. International Journal of Pharmaceutics 2016, 510, 86-99, https://doi.org/10.1016/j.ijpharm.2016.06.003.

11. El-Kased, R.F.; Amer, R.I.; Attia, D.; Elmazar, M.M. Honey-based hydrogel: In vitro and comparative In vivo evaluation for burn wound healing. Scientific Reports 2017, 7, https://doi.org/10.1038/s41598-01708771-8.

12. Harish, T.; Raja, D.; Bharath, S.; Raj B V, B.; Madhavan, V. Development of novel in-situ liquid bandages of diclofenac sodium. Indian Drugs 2013, 50, 25-29.

13. Akturk, O.; Tezcaner, A.; Bilgili, H.; Deveci, M.S.; Gecit, M.R.; Keskin, D. Evaluation of sericin/collagen membranes as prospective wound dressing biomaterial. Journal of Bioscience and Bioengineering 2011, 112, 279-288, https://doi.org/10.1016/j.jbiosc.2011.05.014.

14. Anjum, S.; Sharma, A.; Tummalapalli, M.; Joy, J.; Bhan, S.; Gupta, B. A Novel Route for the Preparation of Silver Loaded Polyvinyl Alcohol Nanogels for Wound Care Systems. International Journal of Polymeric Materials and Polymeric Biomaterials 2015, 64, 894-905, https://doi.org/10.1080/00914037.2015.1030660.

15. Banala, V.T.; Srinivasan, B.; Rajamanickam, D.; Basappa Veerbadraiah, B.; Varadarajan, M. Statistical optimization and in-vitro evaluation of metformin hydrochloride asymmetric membrane capsules prepared by a novel semiautomatic manufacturing approach. ISRN Pharmaceutics 2013, 2013, https://doi.org/10.1155/2013/719196.

16. Lee, S.M.; Park, I.K.; Kim, Y.S.; Kim, H.J.; Moon, H.; Mueller, S.; Jeong, Y.-I.L. Physical, morphological, and wound healing properties of a polyurethane foam-film dressing. Biomaterials Research 2016, 20, https://doi.org/10.1186/s40824-016-0063-5.

17. Kamoun, E.A.; Kenawy, E.-R.S.; Chen, X. A review on polymeric hydrogel membranes for wound dressing applications: PVA-based hydrogel dressings. Journal of Advanced Research 2017, 8, 217-233, https://doi.org/10.1016/j.jare.2017.01.005.

18. Fu, Y.; Kao, W.J. Drug release kinetics and transport mechanisms of non-degradable and degradable polymeric delivery systems. Expert Opinion on Drug Delivery 2010, 7, 429-444, https://doi.org/10.1517/17425241003602259.

19. ICH Guidelines, Geneva: International conference on harmonization of technical requirements for registration of pharmaceuticals for human use, 2003, Accessed from: http://www.ich.org/Q1A(R2).

20. El-Hefian, E.A.; Nasef, M.M.; Yahaya, A.H. Preparation and Characterization of Chitosan/Poly(Vinyl Alcohol) Blended Films: Mechanical, Thermal and Surface Investigations. E-Journal of Chemistry 2011, 8, https://doi.org/10.1155/2011/969062.

21. Matthews, K.H.; Stevens, H.N.E.; Auffret, A.D.; Humphrey, M.J.; Eccleston, G.M. Lyophilised wafers as a drug delivery system for wound healing containing methylcellulose as a viscosity modifier. International Journal of Pharmaceutics 2005, 289, 51-62, https://doi.org/10.1016/j.ijpharm.2004.10.022.

22. Tang, Y.-F.; Du, Y.-M.; Hu, X.-W.; Shi, X.-W.; Kennedy, J.F. Rheological characterisation of a novel thermosensitive chitosan/poly(vinyl alcohol) blend hydrogel. Carbohydrate Polymers 2007, 67, 491-499, https://doi.org/10.1016/j.carbpol.2006.06.015.

23. Kim, J.O.; Park, J.K.; Kim, J.H.; Jin, S.G.; Yong, C.S.; Li, D.X.; Choi, J.Y.; Woo, J.S.; Yoo, B.K.; Lyoo, W.S.; Kim, J.-A.; Choi, H.-G. Development of polyvinyl alcohol-sodium alginate gel-matrix-based wound dressing system containing nitrofurazone. International Journal of Pharmaceutics 2008, 359, 79-86, https://doi.org/10.1016/j.ijpharm.2008.03.021. 